\title{
DIACHRONIC 3D RECONSTRUCTION FOR LOST CULTURAL HERITAGE
}

\author{
G. Guidi ${ }^{\text {a, } * \text {, M. Russo }}{ }^{\text {b }}$ \\ a Mechanical Dept., Politecnico di Milano, via La Masa 1, 20156 Milano, Italy - gabriele.guidi@polimi.it. \\ b INDACO Dept., Politecnico di Milano, via Durando 38/a, 20158 Milano, Italy - michele.russo@polimi.it
}

KEY WORDS: 3D Laser Scanning, Architectural reconstruction, 3D data integration, Polygonal modeling, CAD modeling

\begin{abstract}
:
Cultural Heritage artifacts can often be underestimated for their hidden presence in the landscape. Such problem is particularly large in countries like Italy, where the massive amount of "famous" artifacts tends to neglect other presences unless properly exposed, or when the remains are dramatically damaged leaving very few interpretation clues to the visitor. In such cases a virtual presentation of the Cultural Heritage site can be of great help, specially for explaining the evolution of its status, giving sometimes sense to few spare stones. The definition of these digital representations deal with two crucial aspects: on the one hand the possibility of 3D surveying the relics in order to have an accurate geometrical image of the current status of the artifact; on the other hand the presence of historical sources both in form of written text or images, that once properly matched with the current geometrical data, may help to recreate digitally a set of 3D models representing visually the various historical phases (diachronic model), up to the current one. The core of this article is the definition of an integrated methodology that starts from an high-resolution digital survey of the remains of an ancient building and develops a coherent virtual reconstruction from different historical sources, suggesting a scalable method suitable to be re-used for generating a 4D (geometry + time) model of the artifact. This approach has been experimented on the "Basilica di San Giovanni in Conca" in Milan, a very significant example for its complex historic evolution that combines evident historic values with an invisible presence inside the city.
\end{abstract}

\section{INTRODUCTION}

3D digital models for virtual access to Cultural Heritage have been widely used in the last decade for the increasing interest on their application as ideal repository for archaeological data, conservation records, reconstructive interpretation of lost buildings and web diffusion of cultural contents (Addison, 2000).

Different solutions based on the use of pre-rendered videos of 3D digital models or direct interaction with them has been successfully experimented, showing the communicative value of this first solution (Stumpfel et al., 2003; Beraldin et al., 2002) and the potentiality of the second ones in terms of interaction and real-time definition of paths and unusual points of view (Levoy et al., 2000), or connection of the model with descriptive data (Forte, 2002).

Given a specific monumental building to be approached, the generation of such 3D models can be obtained according with two different criteria: on the one hand faithful representations of the current condition of the monument, employing advanced digital survey techniques such as digital photogrammetry and laser scanning, with a following modeling and representation processes based on true geometrical data. On the other hand the 3D digital reconstructions can be conceived starting from historical information and drawings, with a research approach more oriented to the interpretation of lost architecture.

The first approach presents well defined methodologies that allow to create accurate digital representations of the artefacts as is in present time (Guidi et al., 2010). In the last decade the integration between different survey methodologies were exploited in order to obtain the most accurate digital representation of a real object by improving the features of traditional survey processes (Guidi et al., 2003; Guidi et al., 2002; Beraldin, 2004; El-Hakim et al., 2008; El-Hakim et al., 2008; Guidi et al., 2009).
Instead of this, methods for the definition of archetypal digital models present very different possibilities depending on the historical analysis approach. In the last decade experts in Digital Humanities have analyzed and discussed about the use of virtual interiors and environments representations as effective instrument for clearer diachronic analysis (Frischer et al., 2002; Frisher and Stinton, 2002; Guidi et al., 2008; El-Hakim et al., 2008) and therefore as a tool for discovering new archaeological results stacking on the possibility to "see" what in the past was only possible to be imagined through descriptions. So virtual reconstructions can be considered a new powerful scientific methodology in addition to the more obvious application for increasing the diffusion of archaeological culture among the non experts.

Methodologies with a coherent and acceptable path for creating digital reconstructions of lost buildings or ruins are therefore needed, if scientifically acceptable hypothesis have to be proposed. For this reason the aim of this article is the definition of an integrated methodology that start from an high-resolution digital survey of the remains of an ancient building in order to gain the maximum geometrical knowledge of it, and stack on this for developing a coherent virtual reconstruction through an iterative verification of the different historical sources involved. The process of designing an interactive 3D model representation of a Cultural Heritage monument presents different aspects of complexity. This is why this research deals with two crucial aspect for the whole pipeline: the definition of a methodology that integrate geometrical information extracted from 3D survey and historical data, with the main purpose to identify an optimal process of $3 \mathrm{D}$ reconstruction of lost buildings and the relative representations of their different historical phases, improving the comprehension of the artefact evolution by a diachronic model.

The 3D acquisition and modeling project of San Giovanni in Conca was promoted by the regional government in order to

\footnotetext{
* Corresponding author.
} 
define a reliable methodology for generating 3D digital models of ancient monuments hidden under the surface of Milan and nowadays, with very few exceptions, almost completely lost. For this purpose the application of virtual reality for the visualization of lost architecture in a realistic way was taken into consideration as a mean for giving new life to hidden patrimony, especially interesting for the approaching EXPO 2015 that will be held in Milan.

By this point of view San Giovanni in Conca represented a very significant test for its complex historic evolution. At last it became essential the definition of a non common instruments of valorization of an artefact that combines an evident historic value with an invisible presence inside the city.

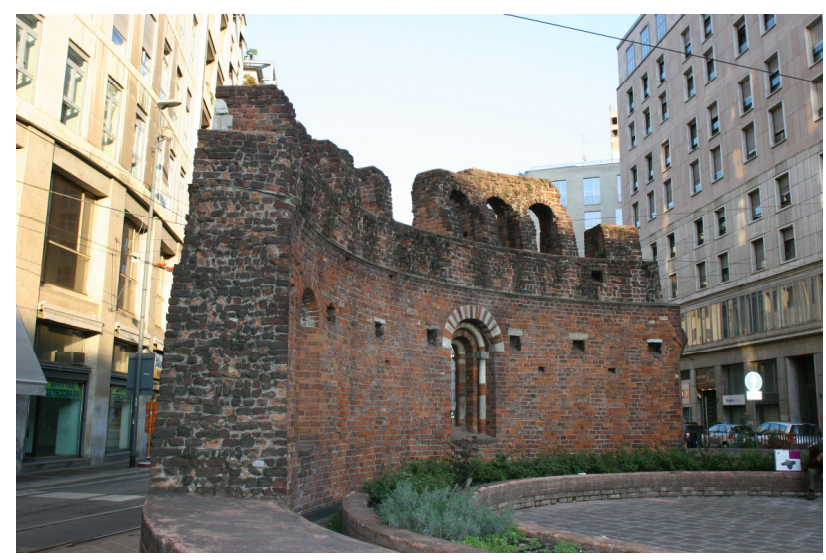

Figure 1. Ancient ruins of the Basilica in actual environment.

\subsection{Historical background of the building}

The rests of San Giovanni in Conca Basilica consist in a little apsidal portion and a crypt located in the center of Piazza Missori in Milan. The reduced dimension of the ruins and their setting ascribe a minor role of the artefact, despite the wellknow importance of the Basilica during the Romanesque period.

Different historic sources place the beginning of the church foundation in the first century B.C. (Bianconi, 1787; Castiglione, 1625; Lattuada, 1737; Torre, 1714) while its conclusion is supposable around the V-VI century A.D. In XI century different decorative and constructive Romanesque alterations were introduced in the church with the addition of a crypt. In the XIV century the ecclesial complex was enlarged and adorned with sculptures and frescoes thanks to Bernabò Visconti's patronage. In XVI century Francesco II Sforza lended the church to Carmelitani Fathers of Mantova congregation and some architectural modification were produced for the official visit of Carlo Borromeo. Beside the church there was a high 24 meters massive bell tower. The period of foundation is not exactly known, but it's well-known that the Carmelitani Fathers increased the height of this part of thirty ells (18 meters) in 1596.

In the next two centuries different modifications and enlargements were brought for the achievement of lateral chapels and architectural restoration. From XVIII century began some troubles of the building: in 1782 the church was taken away from Carmelitani Fathers as a consequence of the abolition of religious orders. Starting from 1808 the church was used by the Corona institution as barracks for Napoleon recruits and in the same year the bell tower was used as astronomic observatory. At the end of this period the deconsecrated church was rented to private customers for warehouse destination. In
1876 Carlo Alberto route was built and in 1879 the town council decided to pull down the front spans of the building and sold it to the Waldensian community who was obliged to rebuild the facade and arrange the residual part of the complex. In the restorations ended in 1881 a new facade was distorted to fit the actual oblique plan, while the bell tower, at that point isolated in the middle of an empty square, was demolished in 1885 .

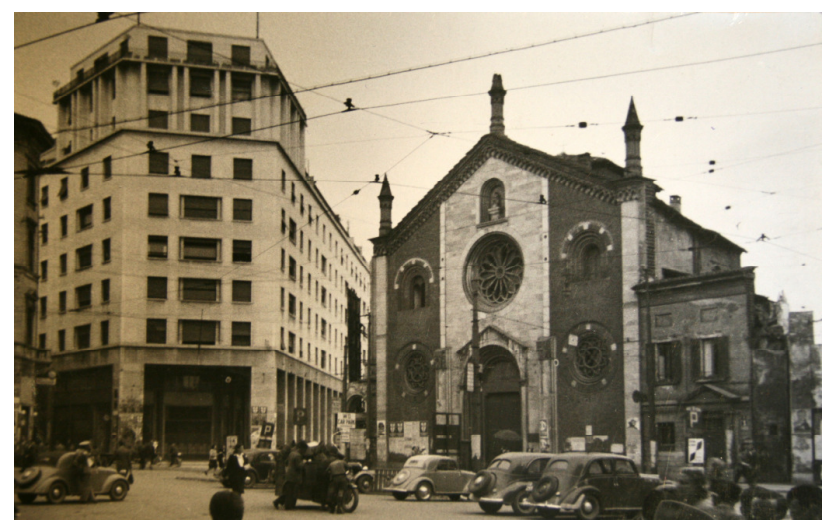

Figure 2. San Giovanni in Conca before 1952.

During the Albertini's Regulating Plan the complete demolition was realized until 1952 saving only the present apsidal ruins and the crypt. The facade was dismantled and reassembled on the new Waldensian church in Francesco Sforza Street.

\section{3D ACQUISITION AND MODELING OF "SAN GIOVANNI IN CONCA"}

\subsection{Instruments}

Different instruments were employed to gain geometrical and material information, supporting the historical and architectural analysis. For acquiring the ruins geometry a 3D Time of Flight scanner (HDS3000) and a triangulation 3D laser scanner (Vivid Minolta 910) were used and two digital reflex cameras (Canon 5D and Canon 400D) for getting textures of the real materials employed. The instrument integration allowed acquiring different level of details of the architecture and materials.

For the historical analysis several literary sources were analyzed, mainly defined by the description of artistic, historic and architectonic evolution, and cadastral and iconographical sources that completed the historical overview. The presence of ancient maps, period plans, drawings and paintings of the church allowed verifying the reliability of the historical sources providing the best interpretation of the past aspect of the building. In this step the pictures of the past period have assumed the crucial role of objective data. All these sources converged to one historic evolution of the artefact characterized by few verified architectural phases.

\subsection{Data Acquisition}

The 3D survey considered a 20x20 meters area composed by a middle-complex hypogeal portion with many columns and capitals and a less-complex external portion without sculpted elements. During the survey project it was decided to use the bigger part of the 3D acquired model as a reference mould for CAD modeling and only the little remaining part as direct information source. This assumption required the definition of a dynamic resolution step in 3D acquisition, starting from $2 \mathrm{~cm}$ 
for architectural portions up to $0.4 \mathrm{~mm}$ for the sculpted ones. Reference targets were not positioned in the survey scene for the evident presence of recognizable three-dimensional features in the environment that were used for aligning the range maps through an Iterative Closest Point (ICP) process.

During the 3D survey the TOF laser scanner HDS3000 was used for the massive 3D acquisition of the architectonic portions of the apse and the crypt while the Vivid 910 instrument was applied in the 3D detailed acquisition of the most interesting capitals in the crypt. A complex network of acquisition points was defined in order to obtain redundant data, avoiding both the geometrical lack due to the shadow effect of the columns and reaching a good precision in the alignment step. The connection between crypt and apse was defined by a crucial range map that linked some detailed portions of the internal part with the external range maps, acquired to survey the external apse from different point of view.

At the end of the ICP alignment a final point cloud of $9 \times 106$ points was obtained, containing all the significant geometrical data on the 3D scene. Although the spatial resolution of 3D data during the acquisition phase was kept at the maximum level, a reasonable trade-off was found re-sampling the geometry at different resolution steps in relation with the historical, architectonical and artistic relevance of the real model, from 20 $\mathrm{cm}$ step for the urban context to $2 \mathrm{~cm}$ for detailed portions. This solution allowed an optimal reduction of the point cloud for the creation of the polygonal model. All data process was carried out inside the Cyclone software (Leica Geosystem).

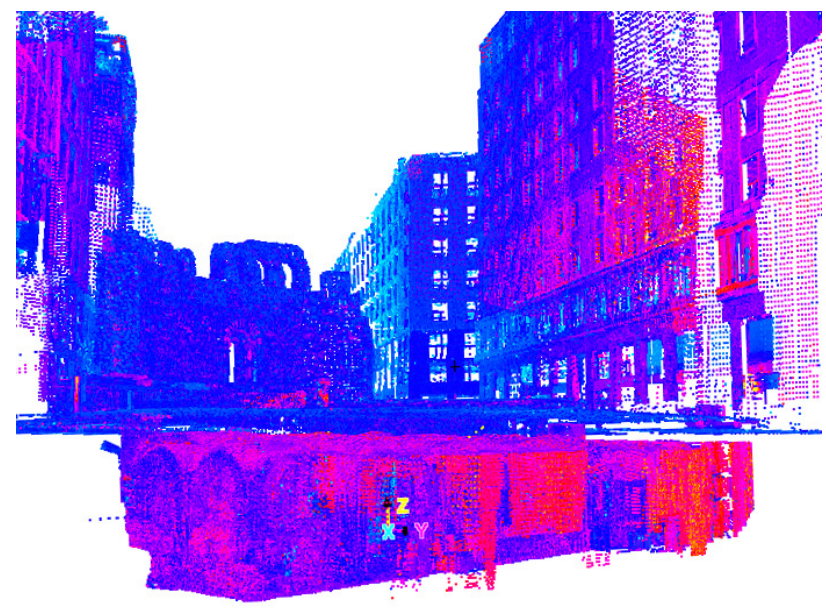

Figure 3. Final aligned point cloud of the crypt, the apsidal ruins and part of the surrounding environment.

At the same time photographs reportage was completed in order to integrate geometric information useful for the CAD reconstruction step and for the definition of a material repository necessary for the texturing phase. The color and dimension data were post-processed to optimize the projection phase of the texture and the real-time visualization of the entire 3D model.

\subsection{Creation of the reality-based model}

Only a portion of the acquired data was processed, obtaining polygonal models coherent with the real geometric characteristics: the Romanesque foundation ruins, the complex of the crypt vaults, the closing portions of the apse wall and the capitals. The others polygonal parts were reduced 40 times from the original resolution, generating a simplified mould suitable for the CAD re-modeling phase. The polygonal editing was carried out inside Rapidform (INUS Technology) and Polyworks (Innovmetric) software.

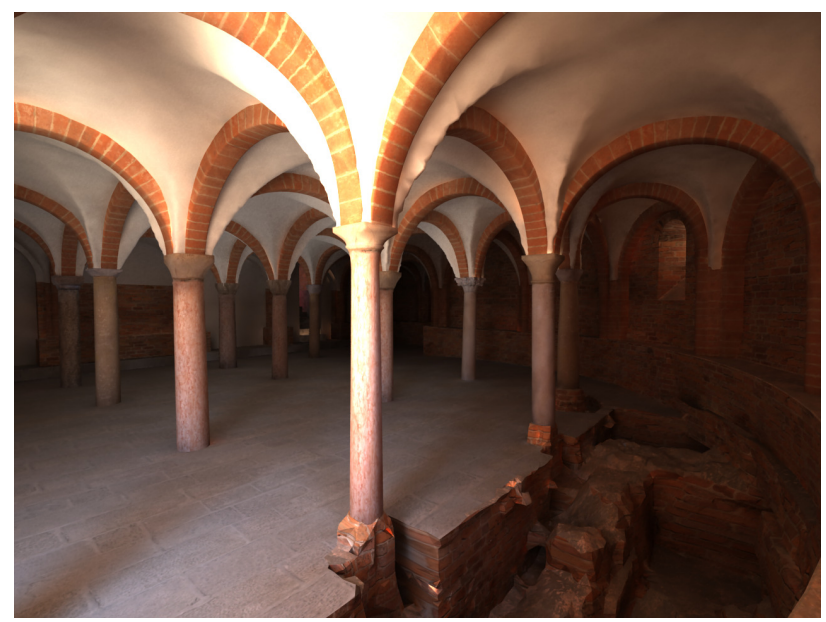

Figure 4. Texturized polygonal model of the real crypt.

Starting from the sections of the reality-based model, a sequence of geometrical shapes was defined inside Rhinoceros software (McNeel) in order to generate a reference framework for a new archetypal geometry. The use of mathematical primitives simplified the digital data management and allowed to create a flexible 3D model, suitable for an iterative interpretation process that implies frequent geometry modification. The distance between the new CAD geometry and the reality-based model was verified to be never above $5 \mathrm{~cm}$. The final model gathers the polygonal surveyed portions and the reconstructed ones in a 210000 polygons digital representation, which was used as base for the application of the texture contained in the materials repository. For the definition of an actual environment of the church an up-to-date urban map was used as reference for the creation of simple building shapes, integrating the space and elevation map information with the geometric data acquired by $3 \mathrm{D}$ laser scanner.
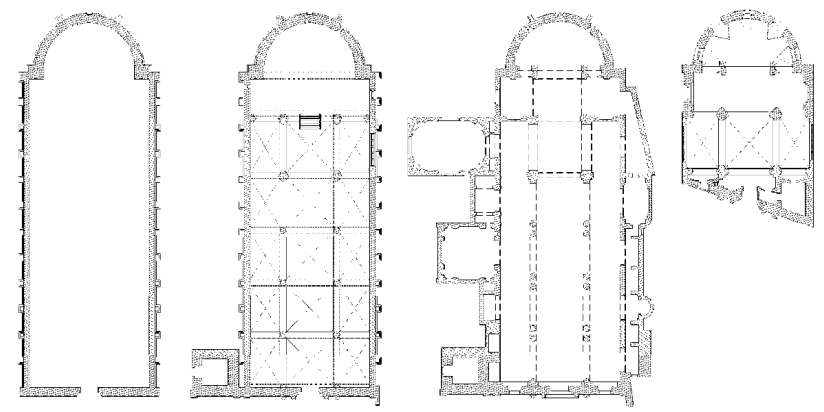

Figure 5. Maps of the church in different historical periods, normalized through the real 3D data: a) VI century; b) XIII century; c) XVI century; d) XIX century.

\subsection{Interpretative 3D model generation}

The first step of the historic reconstruction started from redesigning the past iconographical and cadastral representations with CAD instrument. These historic data lack in objectivity and mutual coherence, due in part for the 
representation style and the graphical instruments, in part for the presence of errors in survey and restitution, the low precision of drawings and the unsuited data preservation.

The lack in objectivity requests a complex step of "translation" and "mediation" between the rough graphic output of the traditional representation technique and the precise CAD geometries reconstruction, maintaining a proportional coherence between the single pars and the whole. The presence of non coherent variation in dimension and proportion between drawings of different historical period can be avoided by an iterative comparison between the traditional representations and the real dimensions coming from the survey.
In this case different sections extracted from the reality-based model were used to rescale the iconographical sources, verifying their correct representation. Starting from the XII century Basilica plan as reference, a complex inspection process of all the other plans, fronts and sections has started in order to reach a sequence of $2 \mathrm{D}$ coherent representation, acceptable from the geometrical and historical point of view. At last the integration between ancient drawings and geometrical measurements contained in the real "revisited" facade of the Waldensian church played an important role for the 3D façade reconstruction.

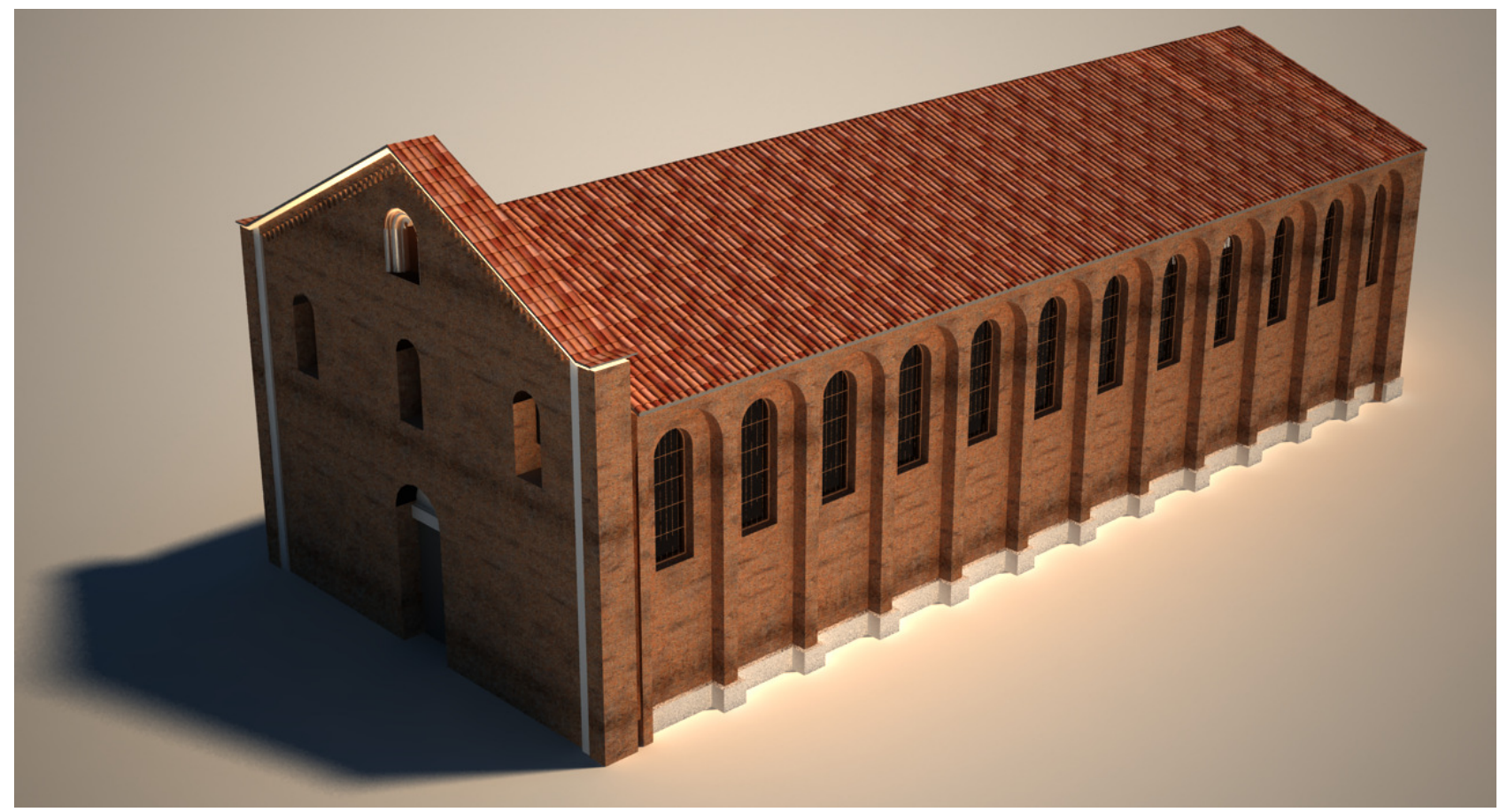

a)

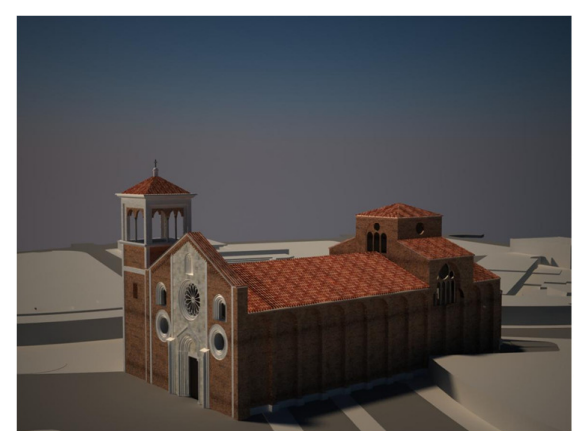

b)

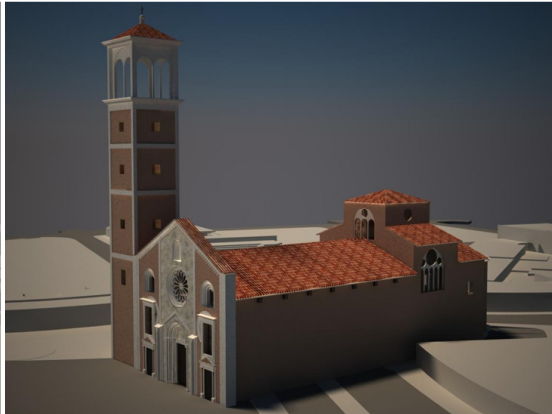

c)

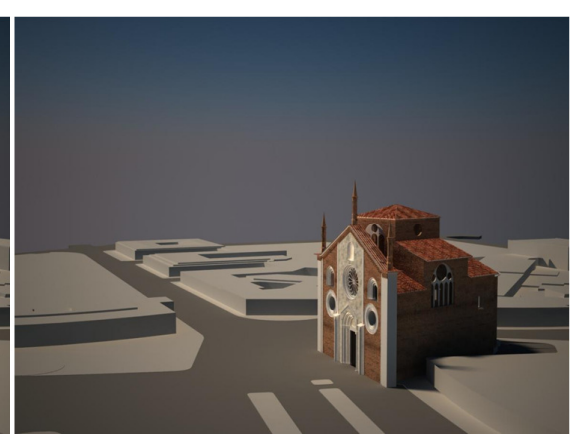

d)

Figure 6. Reconstructed models of the various periods: a) VI century; b) XIII century; b) XVI century; c) XIX century..

The combination between the complex level of 3D representation and the interpretation of reconstructive hypotheses, respecting the constructive and aesthetical rules of the period, represented the bottleneck of this step. A 2D drawing represents a form of incomplete spatial representation, effective for the geometrical description of a particular portion of the architecture but unsuitable for the global knowledge and representation of the entire building. Contrarily in a 3D representation every single element have to be geometrically described since every portion of the digital model is connected with the others in a complex system of spatial relationship. Despite on unavoidable lacks of historical data, such relationship between principal shapes and formal details can be more easily interpreted, thanks to the simultaneous presence of the actual 3D data attainable by laser scanning and ancient drawings. The modeling process, if not supported by historical sources, can be founded on constructive logics supported by an architectural vocabulary and local culture, defined in relation with the formal rules present in other churches nearby San Giovanni in Conca.

\section{FINAL RESULTS}

From historical analysis four different evolutive phases of the architecture evolution have been defined. For the early Christian version of the church (VI century A.D.) the redesign 
process of the walls and roof started from the apsidal portion, using the surveyed model as initial reference. The definition of the second Romanesque version of XII century A.D. period started from the first reference structure of the early Christian Basilica with the addition of a little bell-tower and the introduction of some important constructive elements like a nave, two aisles, a transept and the crypt; the definition of this last element obliged to raise the apsidal floor and to introduce a stairs to reach the most sacred area of the church.

In the third evolution step of XV century A.D. some different architectonical and aesthetical modifications were inserted both in the bell-tower and in the Basilica. The last significant passage of the XVIII century A.D. presented the building in a maimed version preserving only the final part of the nave and aisles and the apse. The materials used to texturize the models considered both the preserved materials of the ruins and some materials acceptable for the period, in relation with local material.

All the CAD models were generated in Rhinoceros software (McNeel) and visualized with V-Ray rendering engine. The sequence of $3 \mathrm{D}$ models of different periods visualized in the same environment suggests a clear instrument of representation of the architectonical evolution of the building.

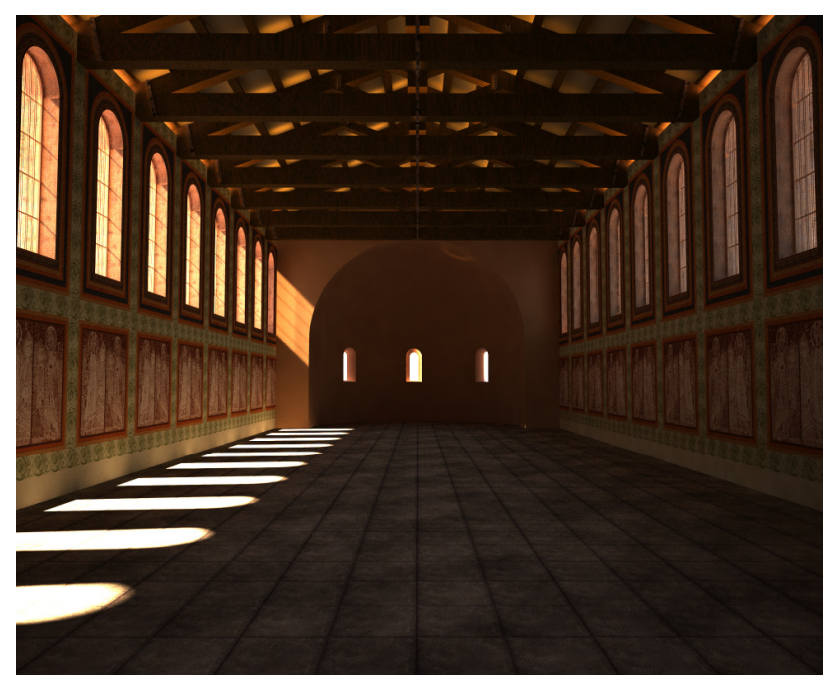

Figure 7. Interior reconstruction of VI century.

The geometrical and material information contained in the $3 \mathrm{D}$ models and the light analysis allow a careful evaluation of the architecture, an ideal starting point for discussion between experts about historical interpretation and modeling variation introduced.

In addition this kind of visualization represents a clearer and more involving instrument of communication for the comprehension of lost Cultural Heritage. Experts can use 3D models as data repository, exploiting the interactive capacities and real-time visualization of the results for critical discussion or analyzing the effects of the dynamic variations of materials and light parameters. The extraction of simple measures or 2D drawings from the 3D model can always be implemented as support for discussions or research in different fields.

\section{CONCLUSIONS}

The main goal of this article regards the definition of a diachronic 3D modeling process for lost Cultural Heritage reconstruction through historical and real data integration.

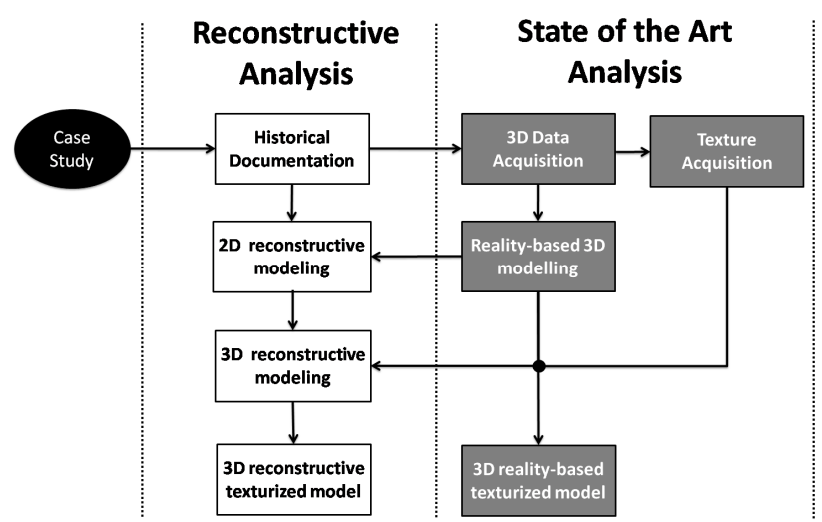

Figure 8. Block diagram of the reconstruction process based on the integration of $3 \mathrm{D}$ measurements and historical analysis.

Starting from a complex historical example, the church of San Giovanni in Conca in Milan, a method based on the integration between bibliographical and iconographical sources and 3D geometrical survey is suggested. Beginning from this approach, the critical aspects that can affect the whole 2D and 3D interpretation process of the church were exploited.

The final results demonstrate that this kind of diachronic visualization represents an interesting "medium" of communication suitable at different levels for experts that can use 3D models as a common field for discussion and analysis about the interpretative choices. In addition virtual reality offers an instrument suitable for the tourist valorization of the church, based on a clearer comprehension of the historic evolution and a more involving representation of the ancient aspects of the external Basilica and the interior ambient.

At present 2D documentation was used as support for the 3D historical church reconstructions. For the future a more effective integration between the 3D models and the historical sources should be investigated, in order to justify better the reconstructive choices, exploiting a database of documents that can be easily linked and visualized at the same time of the model.

\section{ACKNOWLEDGEMENTS}

The authors desire to thanks Prof. Maurizio Boriani, Director of DPA Department at Politecnico of Milan, for the beginning impulse of the project and the support in the historic analysis with some precious considerations on the urban evolutions. Another important thank to Donatella Caporusso, Director of the Archeological Museum of Milan, for the assistance in analysis and archaeological interpretation of the different phases of the Basilica. A special thank to Prof. Paolo Russo, head of the Laboratory of "Topografia and Fotogrammetria" at University of Ferrara for contributing, with a HDS 3000 laser scanner, to the acquisition of the whole church. At the end the authors desire to thank Sebastiano Ercoli for the consistent effort in the 3D modeling and texturing process of the crypt and Laura Micoli and Giorgia Morlando for the support in 3D acquisition and processing data.

\section{REFERENCES}

Addison, A.C., 2000. Emerging trends in Virtual Heritage. IEEE MultiMedia, 7(2), pp. 22-25. 
Beraldin, J. A., 2004. Integration of Laser Scanning and Close range Photogrammetry - the Last Decade and Beyond. In: Proceedings of the XXIth ISPRS Congress, Commission VII, Istanbul, Turkey, pp. 972-983.

Beraldin, J. A., Picard, M., El-Hakim, S.F., Godin, G., Valzano, V., Bandiera, A., Latouche, C., 2002. Virtualizing a Byzantine Crypt by Combining High-resolution Textures with Laser Scanner 3D Data. In: Proceedings of VSMM, Gyeongju, Korea, pp. 3-14.

Bianconi, C., 1787. Nuova guida di Milano per li amanti delle Belle Arti e delle sacre, e profane Antichità Milanesi. Stamperia Sirtori, Milano.

Castiglione, G. A., 1625. Mediolanenses Antiquitates. Pietro Vander, Leiden.

El-Hakim, S., Remondino, F., Voltolini, F., 2008. Integrating Techniques for Detail and Photo-Realistic 3D Modelling of Castles. GIM International, 22(3), pp. 21-25.

El-Hakim, S., Beraldin, J. A., Picard, M., Cournoyer, L., 2008. Surface Reconstruction of Large Complex Structures from Mixed Range Data - The Erechtheion Experience. In: Proceedings of XXI Congress of the International Society for Photogrammetry and Remote Sensing (ISPRS), Beijing, China, Vol. 37, pp. 1077-1082.

El-Hakim, S., Lapointe, J., Whiting, E., 2008. Digital Reconstruction and 4D Presentation through Time. In: Proceedings of the International Conference on Computer Graphics and Interactive Techniques (SIGGRAPH), Los Angeles, California.

Forte, M., 2002. Musealizzare il virtuale: il progetto di allestimento multi-interattivo per la Cappella degli Scrovegni, Computer Gazette, pp. 30-35.

Frischer, B., Niccolucci, F., Ryan, N., Barceló, J. A., 2002. From CVR to CVRO: the Past, Present and Future of Cultural Virtual Reality. In: Proceedings of the VAST EuroConference, Arezzo, Italy, pp. 1-12.

Frisher, B., Stinton, P., 2002. The importance of scientific authentication and a formal visual language in virtual models of archaeological sites: the case of the House of Augustus and Villa of the Mysteries. In: Proceedings of the Conference on Authenticity, Intellectual Integrity and Sustainable Development of the Public Presentation of Archaeological and Historical Sites and Landscapes, Ghent, East-Flanders, pp. 4883.

Guidi, G., Russo, M., Beraldin, J. A., 2010. Acquisizione $e$ modellazione poligonale, McGraw Hill, Milano.

Guidi, G., Remondino, F., Russo, M., Menna, F., Rizzi, A., Ercoli, S., 2009. A multi-resolution methodology for the 3D modeling of large and complex archaeological areas. Special Issue in International Journal of Architectural Computing (IJAC), pp. 39-55.

Guidi, G., Frischer, B., Lucenti, I., Donno, J. Russo, M., 2008. Virtualizing ancient Imperial Rome: from Gismondi's physical model to a new virtual reality application. Digital Matter and Intangible Heritage Issue of International Journal of Digital Cultural Heritage and E-Tourism (IJDCE), pp. 240-252.
Guidi, G., Beraldin, J. A., Ciofi, S., Atzeni, C., 2003. Fusion of range camera and photogrammetry: a systematic procedure for improving 3D models metric accuracy. IEEE Transactions on Systems Man and Cybernetics Part B-Cybernetics, 33(4), pp. 667-676.

Guidi, G., Tucci, G., Beraldin, J-A., Ciofi, S., Ostuni, D., Costantini, F., El-Hakim, S., 2002. Multiscale archaeological survey based on the integration of $3 \mathrm{D}$ scanning and photogrammetry. In: Proceedings of CIPA WG 6 International Workshop on Scanning for Cultural Heritage Recording, Korfu, Greece, pp. 58-64.

Lattuada, S., 1737. Descrizione di Milano, Ed. Biblioteca Milanese, Milano, Tomo II.

Levoy, M., Pulli, K., Curless, B., Rusinkiewicz, S., Koller, D., Anderson, A., Shade, J., Pereira, L., Davis, J., Fulk D., 2000. The Digital Michelangelo Project: 3D scanning of large statues. In: Proceedings of ACM SIGGRAPH, pp. 131-144.

Stumpfel, J., Tchou, C., Hawkins, T., Martinez, P., Jones, A., Emerson, B., Brownlow, M., Jones, A., Yun, N., Debevec P., 2003. Digital Reunification of the Parthenon and its Sculptures. In: Proceedings of 4th International Symposium on Virtual Reality, Archaeology and Intelligent Cultural Heritage (VAST), Brighton, UK.

Torre, C., 1714. Il ritratto di Milano. Luigi Maestri Editore, Milano. 